American J. of Engineering and Applied Sciences 2 (1): 17-24, 2009

ISSN 1941-7020

(C) 2009 Science Publications

\title{
Effect of Manufacturing Stresses to Die Attach Film Performance In Quad Flatpack No-Lead Stacked Die Packages
}

\author{
${ }^{1}$ M.F. Rosle, ${ }^{2}$ I. Abdullah, ${ }^{2}$ S. Abdullah, ${ }^{1}$ M.A.A. Hamid, ${ }^{1}$ A.R. Daud and ${ }^{1,2}$ A. Jalar \\ ${ }^{1}$ School of Applied Physics, Faculty of Science and Technology, \\ ${ }^{2}$ Advanced Semiconductor Packaging Laboratory, \\ University Kebangsaan Malaysia, 43600 UKM Bangi, Selangor, Malaysia
}

\begin{abstract}
Problem statement: Repeated heat cure during assembly processes affected the Die Attach Film (DAF) material properties and the effectiveness touched area that leads to weak die bonding and delamination. Suitable die attached condition and DAF material selection had been evaluated to achieve required reliability performance in the manufacturing of the 3D Quad Flat No-Lead (QFN) stacked die package. Approach: During this study, special attention was given to the development of the residual stresses due to mismatch in the coefficients of thermal expansion of different DAF materials. Both experimental and finite element method were employed to gain a better understanding in a stress development induced between two different type of DAF, different die attach temperature and during the manufacturing process. Differential scanning calorimetry (DSC) was used to measure the changes of heat flow characteristics for both types of DAF. The die bond strength results measured using shear testing machine were compared with the finite element method prediction. Results: Although both DAF samples achieved good reliability performance and passed the Moisture Sensitivity Level 3 test (MSL3) at reflow $260^{\circ} \mathrm{C}$ without any sign of delamination, numerical simulation had demonstrated that the stress development were increased exponentially as the die attach temperature increased. It showed that different DAF gave different values of stresses but presented the same trend which the lowest die attached temperature $\left(100^{\circ} \mathrm{C}\right.$ in comparison with $125^{\circ} \mathrm{C}$ and $\left.150^{\circ} \mathrm{C}\right)$ gave more stress to the die and possibility that the die will have weak adhesion to the substrate was high. Conclusions/Recommendations: Therefore for this case, stress can be relieved by having higher die attached temperature with an adequate bonding force and time, however die attached temperature for both DAF must be used above the glass transition temperature $\left(128^{\circ} \mathrm{C}\right.$ for DAF A and $165^{\circ} \mathrm{C}$ for DAF B) and being controlled not to exceed the crystallization temperature $\left(203^{\circ} \mathrm{C}\right.$ for DAF A and $204^{\circ} \mathrm{C}$ for DAF B) of both DAF.
\end{abstract}

Key words: QFN stacked die, die attach film, finite element analysis

\section{INTRODUCTION}

As the consumer demand continue to push towards miniaturization of wireless devices, more functionality and high performance QFN 3-dimensional packaging has been introduced to accomplish all this goal. This innovation introduced the third or $\mathrm{Z}$ height dimension by stacking another die on the base die using Die Attach Film (DAF) as shown in Fig. 1. 3D packaging offers attractive way to reduce transmission delays, since its configuration provides much shorter access to several surrounding chips ${ }^{[1]}$. However, as the number of die stacks increases, DAF on the top die would experience decrease heating temperatures during top die attach process, higher power dissipation and higher thermal resistance between bottom and top die which may lead to weak adhesion and delamination due to high stress concentration ${ }^{[2,3]}$.

There are two common adhesive material used for die stacking in the microelectronic packaging i.e., epoxy paste and DAF. Difficulties in controlling of resin bleed, fillet height, die tilt and adhesive bond-line thickness, has lead to the consideration of DAF as a suitable die attach adhesive for stacked-die applications $^{[4]}$.

By comparison to epoxy, the DAF requires some bonding delay and temperature to allow the DAF to melt, solidifies and stick to the leadframe or die. Previous study has indicated that most of the die stress is developed during die attach and curing process ${ }^{[2,3,5-7]}$. When the die stress in the assembly processes is

Corresponding Author: M.F. Rosle, School of Applied Physics, Faculty of Science and Technology, University Kebangsaan Malaysia, 43600 UKM Bangi, Selangor, Malaysia Tel: +603-89213873 Fax: +603-89213777 
Am. J. Engg. \& Applied Sci., 2 (1): 17-24, 2009

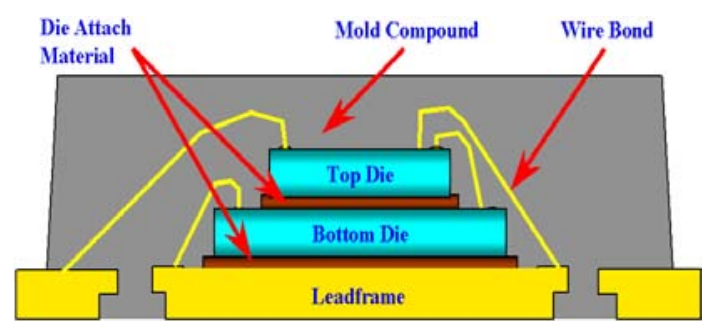

Fig. 1: Stacked die QFN package

compared, it is found that DAF showed $42 \%$ lower stress than epoxy ${ }^{[7]}$. After die attach process, the curing reaction of DAF should be stable in the subsequent process before mold, to increase the effective touched areas and prevent weak interface or delamination in the stack die product ${ }^{[8]}$.

Results from a study by ${ }^{[9]}$ showed that process condition and material properties related to polymeric materials give high impact to the surface mount adhesion. This study reports present work on the evaluation of the material, process and design factors which were studied by scanning acoustic microscopy and finite element analysis. The finite element analyses were implemented to address the stress distribution in the stacked die package and verified by the scanning acoustic microscopy.

\section{MATERIALS AND METHODS}

In this study, two types of DAF (A and B) have been simulated and examined. Temperature for manufacturing process was used as the environment load in the simulation. Fig. 2 shown the standard manufacturing process and corresponding temperature used in this study. The normal curing process was simulated because at this temperature, the cross link process happened. Comparison between two types of DAF was done to see the stress for each process.

Samples were prepared using thin film of $\mathrm{Al}$ die with the package size of $7 \times 7 \times 0.9 \mathrm{~mm}^{3}$, QFN 48 leads package (Fig. 3). The base die size is $5 \times 5 \mathrm{~mm}^{2}$ and the top die size is $3.3 \times 3.3 \mathrm{~mm}^{2}$, where thickness for both dies are $0.15 \mathrm{~mm}$. Two type of DAF (DAF A and B) were used to stack up the top die on the bottom die using ESEC 2008HS die bonding machine.

This experiment was designed to evaluate the die bonding reliability of the DAF and to understand the sources that affect the manufacturing variation during die attach process. A common parameter set was established for the DAF system that allowed both DAF to produce die bonding process that met standard production physical and visual inspection quality.

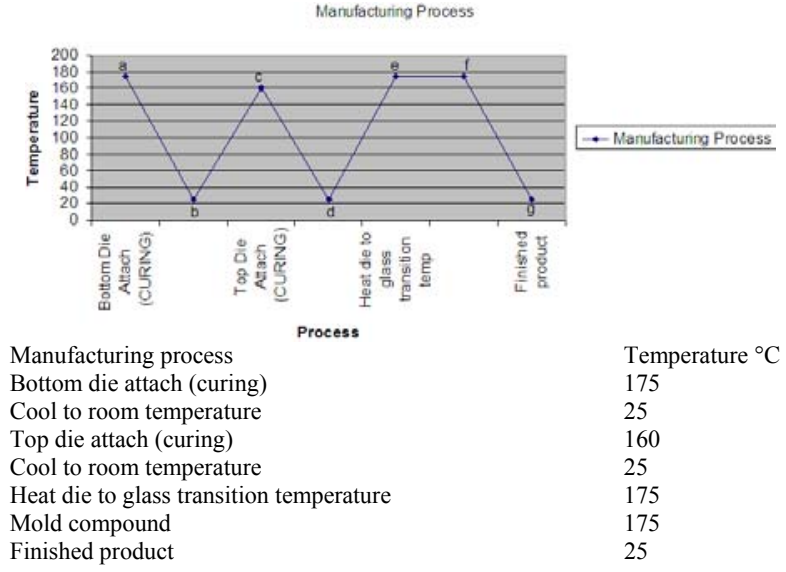

Fig. 2: Standard manufacturing process and corresponding temperatures used in this study

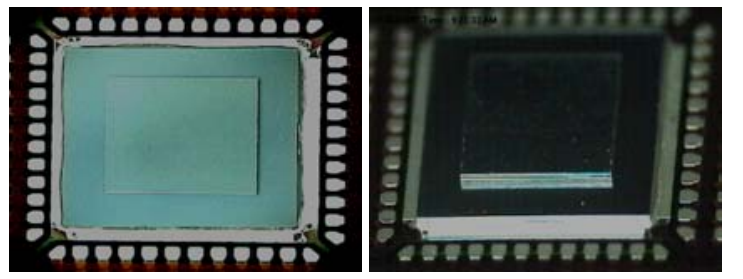

Fig. 3: Top view and side view of the unmolded, 48 leads QFN stacked die package

Based from the data sheet given by the supplier, the recommended temperature range for die attach process are within $100 \sim 150^{\prime} \mathrm{C}$. Thus, in the next simulation will compare three different top die attach temperatures which are 100,125 and $150^{\circ} \mathrm{C}$. Each of the combinations was run as a separate assembly lot randomly.

In the previous study, evaluation on die pick up condition have been made to observe the effect of pick up force, needle size and height on the die crack and needle mark. The study is important to ensure that any failure at pick up process will not affect the bonding while running the die bond evaluation. The Final result concluded that 5 mil needle type with force $50 \mathrm{gf}$ and $0.6 \mathrm{~mm}$ needle height is able to give good pick up condition with no needle mark or die crack for both types of DAF.

Completely flat contact surface is very important to ensure maximum adhesion between DAF and bottom die. It was observed that the contact area between DAF and bottom die surface which affected by needle mark can create voids and lead to delamination. During encapsulation process, air will be trapped in between the needle mark at DAF surface and bottom die that will results in delamination after prolonged reliability 
test. Fig. 4 illustrated the comparison of poor and good DAF surface after die pick-up process.

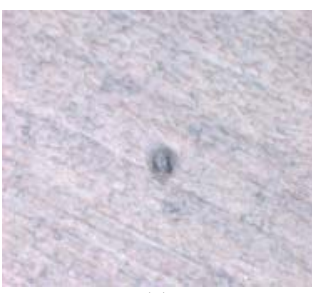

(a)

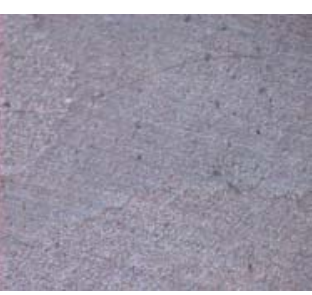

(b)
Fig. 4: Die pick up results (a) needle mark observed (b) no needle mark observed with optimized pick up condition

Differential Scanning Calorimetry (DSC): Mettler Toledo DSC 821e was used to determine the glass transition temperatures $\left(\mathrm{T}_{\mathrm{g}}\right)$, crystallization temperature $\left(T_{c}\right)$ and melting temperature $\left(T_{m}\right)$ of DAF. The studies were carried out for $30-350^{\circ} \mathrm{C}$ with heating rate of $20^{\circ} \mathrm{C}$ $\min ^{-1}$.

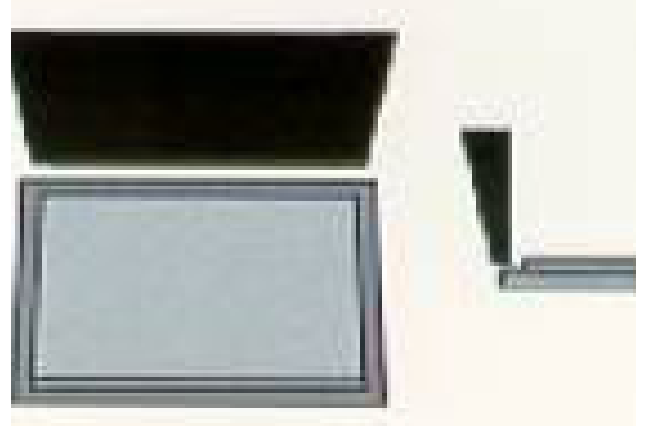

Fig. 5: Correct position of shear tool for top die shear test.

Die shear: Mechanical adhesion strength of DAF was obtained using a XYZTEC Condor shear testing machine. Correct position of shear tool is as shown in Fig. 5. In this study, only the top die was sheared or forced to move while the base die was kept stationary. Results from this study presented the adhesion strength for DAF die attach condition.

Scanning acoustic test: Scanning Acoustic Microscope (SAM) EVO II was used by performing G-scan mode for image analysis and signal amplitude was verified by A-scan mode to detect air gap or interfacial delamination between mold compound and top die, bottom die and leadframe on more than 70 samples of DAF A and B.
Finite Element Analysis (FEA): Finite element technique is a method of finding approximate mathematical solutions of physical problems. It is also used to predict the failure caused by package warpage in semiconductor industry ${ }^{[10]}$. In this study, three dimensional solid models were generated to determine the thermally induced stresses under different conditions of assembly processes. Ansys ${ }^{\circledR}$ software was used for finite element analysis. As the geometry of package is symmetry, only one-quarter of the package is needed to be modeled with symmetrical boundary conditions. The FEA model of package unit is shown in Fig. 6. The model used eight node 3D brick elements and 200 mesh elements to generate quad meshing. The symmetrical boundary conditions were applied to the surface at $\mathrm{x}=0$ and $\mathrm{y}=0$ and node at bottom of substrate to prevent free rigid body motion. Thermal loading is applied to simulate the cooling after molding process, i.e., from $175^{\circ} \mathrm{C}$ to room temperature. Element birth and death option was used to simulate the manufacturing conditions.
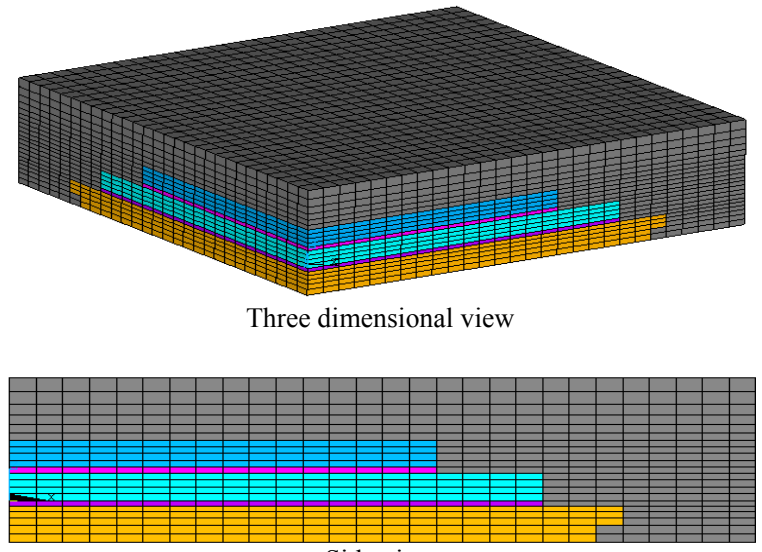

Side view

Fig. 6: The FEA model of QFN stacked die package unit used in this study

\section{RESULTS}

DAF curing properties: DSC was run in dynamic mode to measure the changes of heat flow characteristics for both types of DAF when they were heated under controlled temperatures. The DSC curves in Fig. $7 \mathrm{a}$ and $\mathrm{b}$, present the glass transition temperature, starting point of polymerization temperature, maximum of reaction temperature and rate of cristalinity of DAF A and B. 


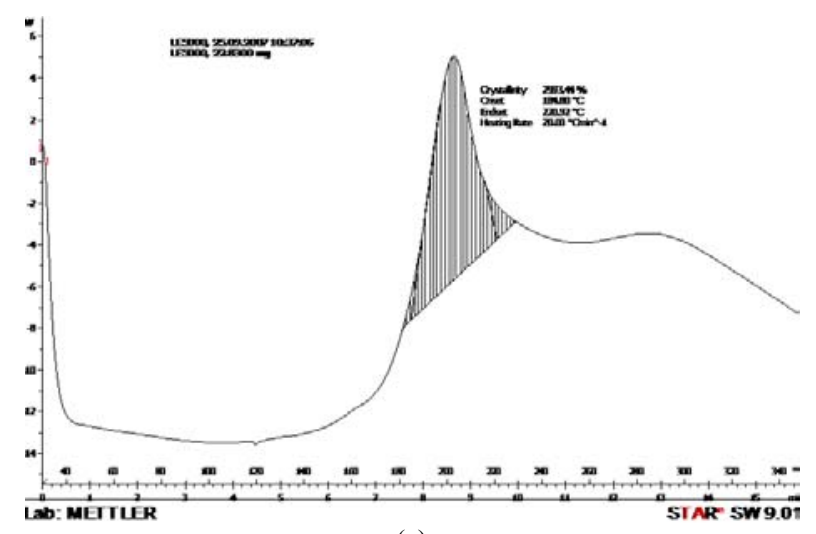

(a)

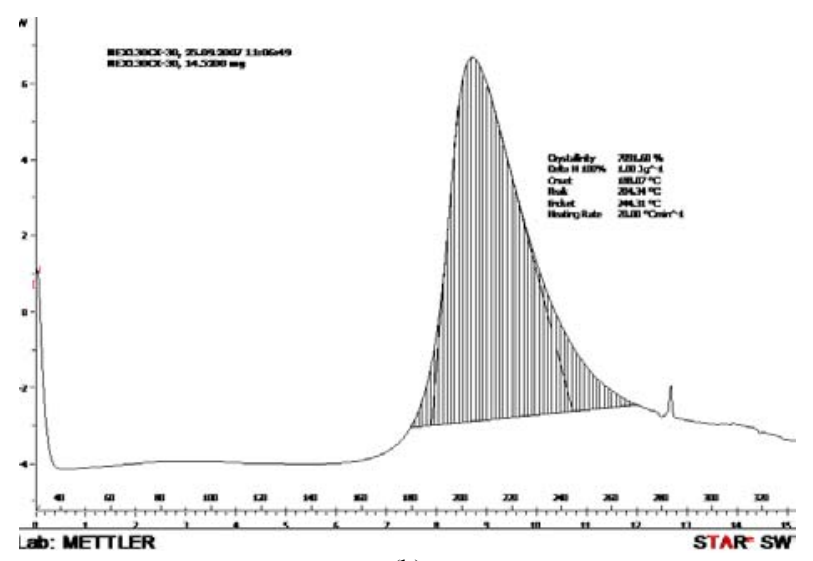

(b)

Fig. 7: (a): DAF A DSC trace at $30-350^{\circ} \mathrm{C}$ with heating rate of $20 \mathrm{~min}^{-1}$ (b): DAF B DSC trace at 30$350^{\circ} \mathrm{C}$ with heating rate of $20^{\circ} \mathrm{C} \mathrm{min}-1$

Die shear result: Fig. 8 shows the comparison of shear strength results for DAF A and B at different die attached processing temperature. Two failure modes were observed during die shear test which were $50 \%$ to $100 \%$ silicon remains on die pad and no silicon remain or less than $10 \%$ on die pad as shown in Fig. 9.

Delamination result: Scanning Acoustic Microscopy (SAM) with G-scan and A-scan mode works by directing focused sound from a transducer on a target object and the transmitted sound was measured. G-scan mode images of DAF A and B after Moisture Sensitivity Level 3 (MSL3) test at reflow $260^{\circ} \mathrm{C}$ are shown in Fig. 10.

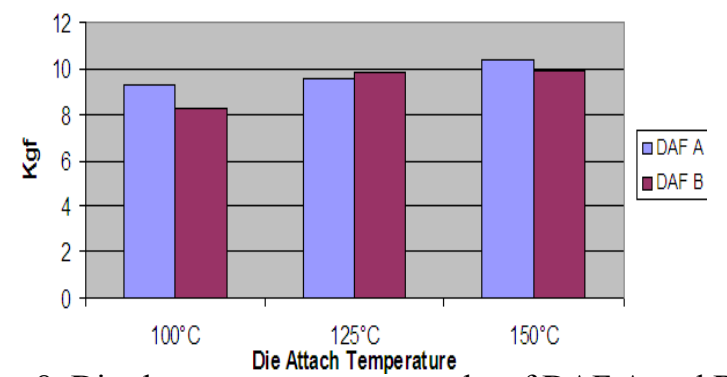

Fig. 8: Die shear measurement results of DAF A and B

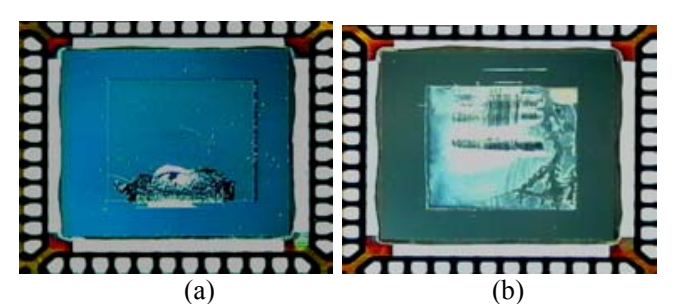

Fig. 9: Specified modes for die shear (a) $50 \%$ to $100 \%$ silicon remains on die pad (b) no silicon remain or less than $10 \%$ on die pad

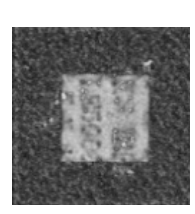

DAF A
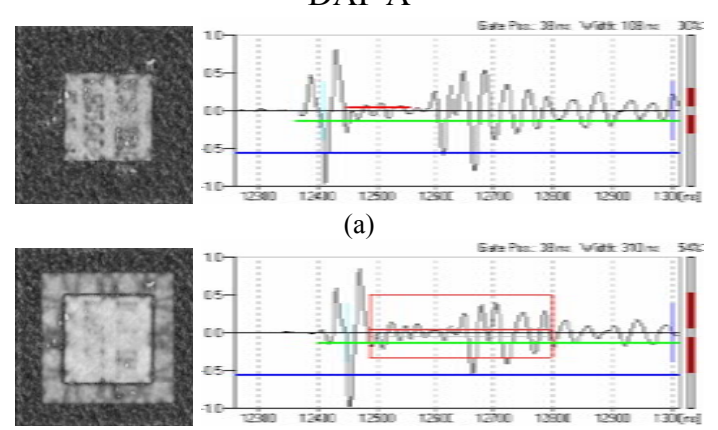

(a)
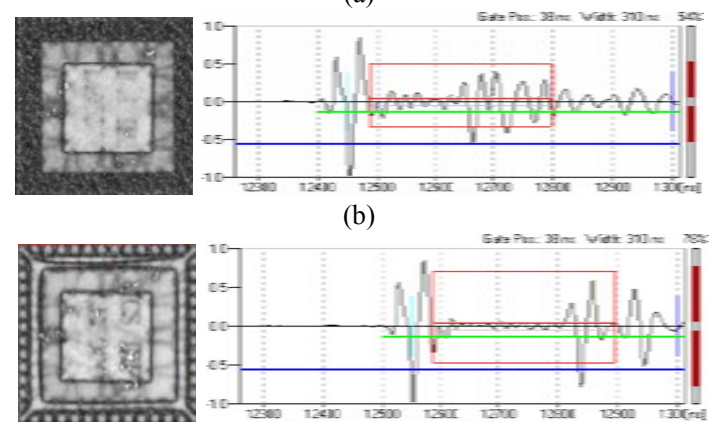

(b)

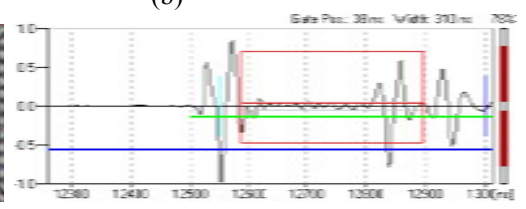

(c)
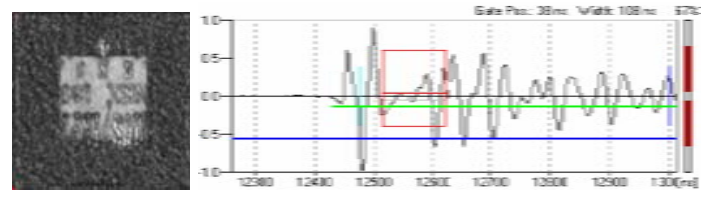

(a)
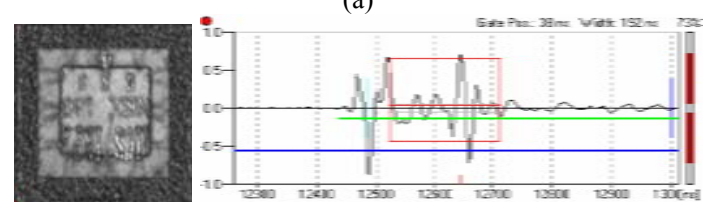

(b) 

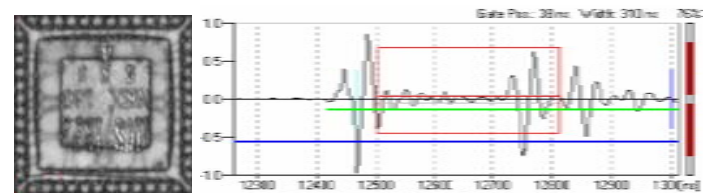

(c)

Fig. 10: G-scan images and A-scan signals show nondefect area and good amplitude (positivenegative-positive) signals for units of DAF A and B after MSL3 test

Stress analysis in FEA technique: Stress distribution on top die laminated with DAF A and B during curing process at $160^{\circ} \mathrm{C}$ and after curing process at room temperature $\left(25^{\circ} \mathrm{C}\right)$ was shown in Fig. 11 and 12. While Fig. 13 presents the stress level experienced along manufacturing process for top die shear stress and top die 1st principal stress of both DAF A and B. Effect of die attach temperature towards top die shear stress and top die 1st principal stress for both DAF A and B were also evaluated as represents by Fig. 14 and 15. Stress values were summarized in Table 1.

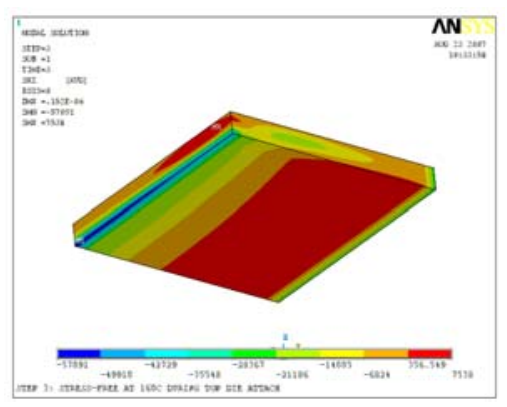

(a)

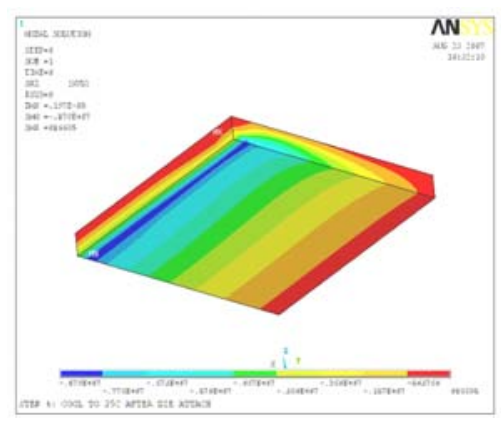

(b)

Fig. 11: Stress distribution on top die laminated with $\mathrm{DAF} A$ at (a) curing process, $160^{\circ} \mathrm{C}$ and (b) room temperature $\left(25^{\circ} \mathrm{C}\right)$ after curing process

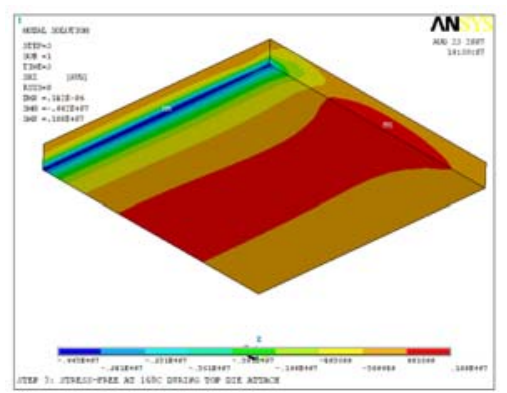

(a)

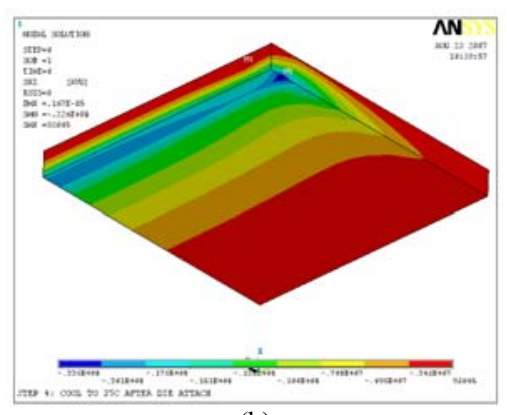

(b)

Fig. 12: Stress distribution on top die laminated with $\mathrm{DAF} \mathrm{B}$ at (a) curing process, $160^{\circ} \mathrm{C}$ and (b) room temperature $\left(25^{\circ} \mathrm{C}\right)$ after curing process

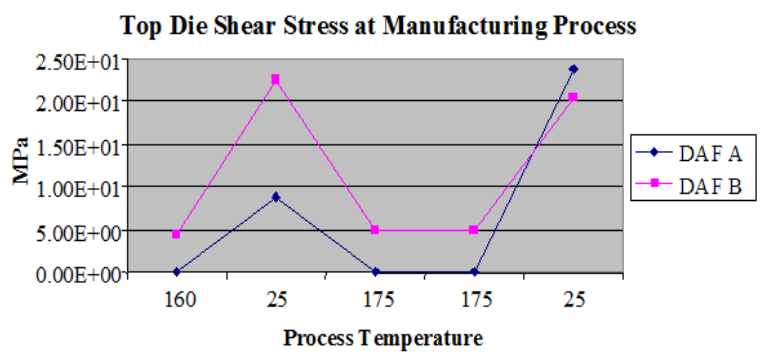

(a)

Top Die 1st Principal Stress at Manufacturing Process

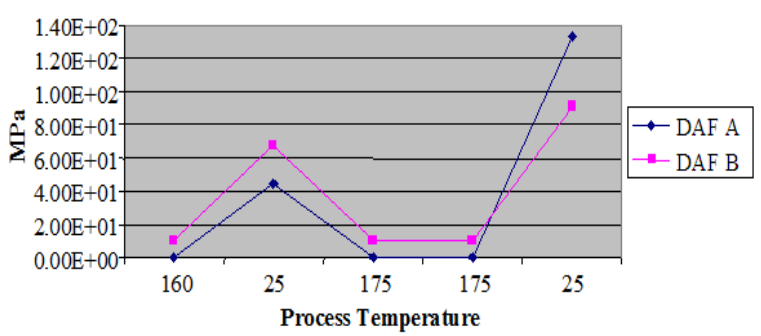

(b)

Fig. 13: Stress level at manufacturing process (a) top die shear stress (b) top die 1st principal stress 
Top Die Shear Stress @ Different Process Temperature For DAF A

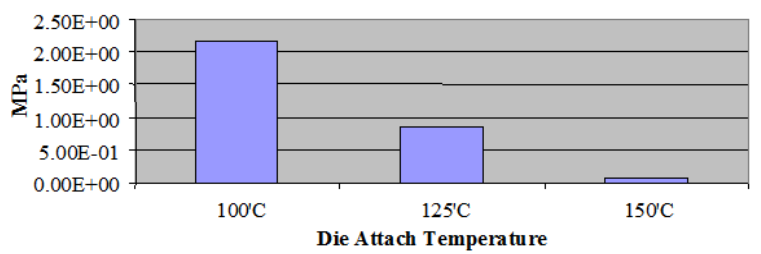

(a)

Top Die $1^{\text {st }}$ Principal Stress@ Different Process Temperature For DAF A

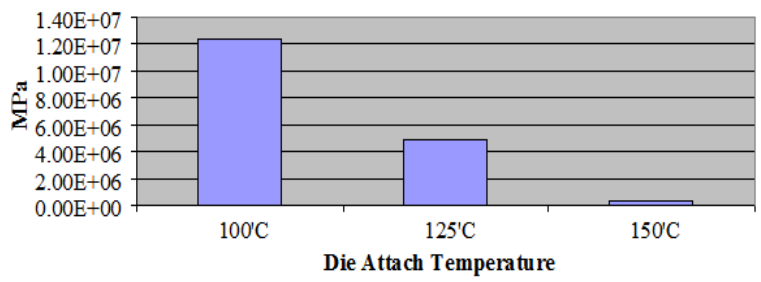

(b)

Fig. 14: Stress level for DAF A at different die attached temperature (a) top die shear stress (b) top die 1 st principal stress

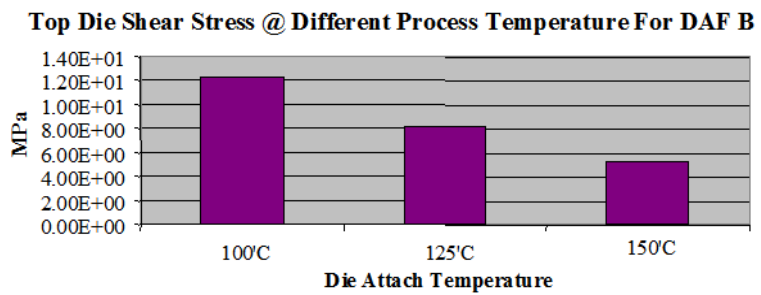

(a)

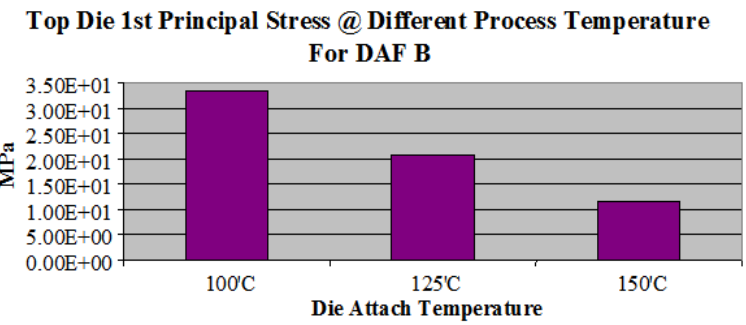

(b)

Fig. 15: Stress level for DAF $B$ at different die attached temperature (a) top die shear stress (b) top die 1 st principal stress

Table 1: Stress values of top die shear stress and top die 1st principal stress for DAF A and B

\begin{tabular}{lll}
\hline Shear stress & DAF A & DAF B \\
\hline $100^{\prime} \mathrm{C}$ & $2.17 \mathrm{~Pa}$ & $1.23 \times 10^{1} \mathrm{~Pa}$ \\
$125^{\prime} \mathrm{C}$ & $8.43 \times 10^{-1} \mathrm{~Pa}$ & $8.15 \mathrm{~Pa}$ \\
$150^{\prime} \mathrm{C}$ & $6.55 \times 10^{-2} \mathrm{~Pa}$ & $5.25 \mathrm{~Pa}$ \\
1 st principle stress & DAF A & DAF B \\
$100^{\prime} \mathrm{C}$ & $1.24 \times 10^{7} \mathrm{~Pa}$ & $3.33 \times 10^{1} \mathrm{~Pa}$ \\
$125^{\prime} \mathrm{C}$ & $4.86 \times 10^{6} \mathrm{~Pa}$ & $2.08 \times 10^{1} \mathrm{~Pa}$ \\
$150^{\prime} \mathrm{C}$ & $3.56 \times 10^{5} \mathrm{~Pa}$ & $1.18 \times 10^{1} \mathrm{~Pa}$ \\
\hline
\end{tabular}

\section{DISCUSSION}

DAF curing properties: Change in DAF curing properties is depending upon the processing temperature (Fig. 7a and b). Knowledge on how these changes occur can guide to a better understanding and help to define the required processing technique. As the temperature increases to some point, the DAF material experienced change in heat capacity and caused the glass transition to occur. The glass transition temperatures $\left(T_{\mathrm{g}}\right)$ of DAF A and B are 128 and $165^{\circ} \mathrm{C}$ respectively. Further heating beyond this temperature caused the DAF materials become less viscous where molecules of the materials gained sufficient energy to spontaneously arrange themselves into a crystalline form. The crystallization temperature $\left(\mathrm{T}_{\mathrm{c}}\right)$ of DAF A and DAF B are at 203 and $204^{\circ} \mathrm{C}$ respectively. The transition from amorphous to crystalline solid is an exothermic process and results in a peak in the DSC signal ${ }^{[11]}$. Ideally, the recommended cure conditions should be followed, with the understanding that the true bondline temperature of the DAF may not necessarily be identical to the oven set temperature ${ }^{[12]}$.

Die shear strength: From Fig. 8 it can be seen that the bonding temperature give a significant impact to the adhesion strength of the top die where both DAF showed the increase in shear strength as the die attach temperatures increase with most of the failure modes were $50-100 \%$ silicon die remained on die pad after shearing and very small number of units illustrated no silicon remain on the die pad (Fig. 9). The adhesion between DAF and bottom die has primarily involved micro interlocking process. Therefore increasing in the die attach temperature above the DAF glass transition temperature caused the viscosity to drop and bonding pressure will force the DAF to achieve intimate contact to the bottom die surface. These influenced the interlocking which lead to the increased in real contact area. As the results, adhesion strength between DAF and bottom die surface had presented high shear strength.

Delamination: Any air gap or delamination will be exhibited as a red area in the SAM image for G-scan mode and negative-positive-negative signal amplitude for A-scan mode. MSL3 test results indicated that most samples of DAF A and B had passed with unsigned of delamination or adhesive voids can be found based on the J-STD-020C Joint IPC/JEDEC Standard for Moisture/Reflow Sensitivity Classification for Nonhermetic Solid State Surface-Mount Devices (Fig. 10). 
Stress analysis in FEA technique: The simulation study on evaluation of the stress induced by thermal loading during assembly process showed that a high stress had been detected at both DAF during cooling down to room temperature after curing process during cooling process. The distributed shear stresses on top die laminated with DAF were decrease exponentially (Fig. 11 and 12). Fig. 13 shows DAF A experienced lower stress level compared to DAF B after curing process. However after the curing process, the stress level of them seems reverse where DAF B exhibited lower stress compared to DAF A. This suggested that DAF A has a better integrity compared to DAF B. Based from the data sheet given by the supplier, the recommended temperature range for die attach process are within $100 \sim 150^{\prime} \mathrm{C}$. Thus, in the next simulation will compare three different top die attach temperatures which are 100,125 and $150^{\circ} \mathrm{C}$. Each of the combinations was run as a separate assembly lot randomly.

Fig. 14 shows that the same trend was obtained between top die shear stress and top die 1st principal stress during processing temperatures of DAF A. Each processing temperatures has presented different stress values. At $100^{\circ} \mathrm{C}$ of die attached temperature, a high stress was obtained on the top die component. The possibility that the die will have weak adhesion at the bottom die was high. At $150^{\circ} \mathrm{C}$ of die attached temperature, the die stress was relieved by showing the lowest stress values compared with other two temperatures $\left(100\right.$ and $\left.125^{\circ} \mathrm{C}\right)$.

Fig. 15 shows that the same trend was obtained between top die shear stress and top die 1st principal stress during processing temperatures of DAF B. Similar with the trend of DAF A, the lowest stress obtained at $150^{\circ} \mathrm{C}$ die attached temperature and the highest stress obtained at $100^{\circ} \mathrm{C}$ die attached temperature. However, the stress result for each die attach temperatures did not show approximate values between top die shear stress and top die 1st principal stress as presented by DAF A.

\section{CONCLUSION}

The experimental and finite element method is design to obtained suitable die attach condition and DAF characterization to achieve MSL3 reliability performance in the manufacturing of the 3D QFN stacked die package. It is suggested that the die attached temperature for DAF A and B must be used above the glass transition temperature $\left(128^{\circ} \mathrm{C}\right.$ for $\mathrm{DAF} \mathrm{A}$ and $165^{\circ} \mathrm{C}$ for DAF B) and being controlled not to exceed the crystallization temperature $\left(203^{\circ} \mathrm{C}\right.$ for DAF A and $204^{\circ} \mathrm{C}$ for DAF B). The best die attach process is characterized by stable values of DAF thermal resistance properties and optimum touched area between DAF and die surface. Although both DAF samples achieved good adhesion and reliability performance, numerical simulation indicates that it is important to control the stress development at the die attach stage, therefore for this case, stress can be relieved by having higher die attach temperature with an adequate bonding force and time.

\section{ACKNOWLEDGEMENT}

The authors would like to thanks the Malaysian government for financial support under IRPA project 03-02-02-0122-PR0075 and Universiti Kebangsaan Malaysia (UKM-OUP-FST-2008). Special thanks to AIC Semiconductor Sdn. Bhd. for assistance in providing experimental facilities.

\section{REFERENCES}

1. Heikkila, R., J. Tanskanen and E.O. Restolainen, 2002. Reliability study of 3D stacked structures. 52nd Electronic Components and Technology Conference, May 28-31, IEEE Xplore, San Diego CA., pp: 1449-1453. DOI: 10.1109/ECTC.2002.1008297.

2. Jalar, A., M.F. Rosle and M.A.A. Hamid, 2008. Die attach film performance in 3D QFN stacked die. Applied Theor. Mech., 3: 104-113. http://www.worldses.org/journals/mechanics/mech anics-2008.htm

3. Tsai, T.Y., H.C. Chang, W.C. Li, C.P. Teng and Y.S. Lai, 2007. Working temperature characterizations for die attach films in stacked-die process. 32nd International Symposium on Electronic Manufacturing Technology, Oct. 3-5, IEEE Xplore, San Jose, CA., pp: 92-95. DOI: 10.1109/IEMT.2007.4417058.

4. Mallik, D., K. Radhakrishnan, J. He, C.P. Chiu, T. Kamgaing, D. Searls and J.D. Jackson, 2005. Advanced package technologies for high performance systems. Intel ${ }^{\circledR}$ Technol. J., 9: 259-272.

http://download.intel.com/technology/itj/2005/volu me09issue04/art01_advpackagetech/vol09_art01.p df

5. Song, S.N., H.H. Tan and P.L. Ong, 2005. Die attach film application in multi die stack package. 7th Electronics Packaging Technology Conference, Dec. 7-9, IEEE Xplore, Singapore., pp: 848-852. DOI: 10.1109/EPTC.2005.1614517.

6. Walwadkar, S.S. and J. Cho, 2006. Evaluation of die stress in MEMS packaging: Experimental and theoretical approaches. IEEE Trans. Components Packag. Technol., 29: 735-742. DOI: 10.1109/TCAPT.2006.885931. 
7. Tsao, P.H. and A.S. Voloshin, 1994. Manufacturing stresses in die due to die attach process. 44th Electronic Components and Technology Conference, May 1-4, IEEE Xplore, Washington D.C., pp: 255-259. DOI: 10.1109/ECTC.1994.367623.

8. Ahmad, I., N.N. Bachok, N.C. Chiang, M.Z.M. Talib, M.F. Rosle, F.L.A. Latip and Z.A. Aziz, 2007. Evaluation of different die attach film and epoxy pastes for stacked die QFN package. 9th International Conference on Electronics Packaging Technology, Dec. 10-12, IEEE Xplore, USA., pp: 869-873. DOI: 10.1109/EPTC.2007.4469691.

9. Chung, C.L. and S.L. Fu, 2003. A study on the characteristic of UV cured die-attach films in stack CSP (Chip scale package). 15th International Conference on Microelectronics, Dec. 9-11, IEEE Xplore, USA., pp: 365-368. DOI: 10.1109/ICM.2003.1287836.
10. Takeda, S. and T. Masuko, 2000. Novel die attach films having high reliability performance for leadfree solder and CSP. 50th Electronic Components and Technology Conference, May 21-24, IEEE Xplore, Las Vegas., pp: 1616-1622. DOI: 10.1109/ECTC.2000.853432.

11. Shoraka, F., K. Kinsman, B. Natarajan and C. Gealer, 1986. Package and molding compound mechanics. 6th International Electronic Packaging Conference, Sep. 25-28, Atlanta., pp: 294-312. http://www.dfrsolutions.com/pdfs/relaxation.pdf

12. Harper, C.A., 2005. Electronic Packaging and Interconnection Handbook. 4th Edn., McGraw Hill, New York, USA., pp: 2.12-2.17. ISBN: 10: 0071430482. 